\title{
Job Satisfaction of Self-Employed Workers: Empirical Evidence from Cameroon Data
}

\author{
${ }^{1}$ Juliette laure Mathou Tchinda \\ ${ }^{2}$ Prof. Huasng Rong Bing \\ ${ }^{1,2}$ Guangdong University of Technology, China
}

\begin{abstract}
This study aims at contributing to the debate opposing results-based utility to procedural utility by evaluating the effect of self-employment on job satisfaction. Data is taken from the second Cameroonian Household Survey (2015). Many propensity scores matching techniques were used in addition to models of qualitative variables which led to the conclusion that self-employed workers are more satisfied with work than employees. This satisfaction is felt despite the fact that self-employment generates low income, almost has no job security and calls for long working hours. The high level of autonomy enjoyed by self-employed workers explains this result, which is in line with the procedural utility approach. Furthermore, this study shows that self-employed workers by necessity are less satisfied than self-employed workers by opportunity, meaning that the level of satisfaction varies.
\end{abstract}

Keywords: Satisfaction, Self-employed worker, Scores method, Cameroon.

\section{Introduction}

Previous works on satisfaction reveal that, as compared to employees, self-employed workers: (1) have a lower and more volatile average income (Hamilton, 2000; Krashinski, 2004; Carrington et al, 1996; Carrington, McCue, and Pierce, 1996 and Kawaguchi, 2003); (2) spend more time at work (Hyytinen and Ruuskanen, 2007), and (3) have a more risky portfolio (Moskowitz and Vissing Jorgensen 2002). Thus, considering traditional microeconomics, one may conclude that self-employed workers are less satisfied than employees. However, previous studies demonstrate that they are more satisfied with their work than employees (Benz and Frey, 2008; Hundley, 2001; Hamilton, 2000; Blanchflower and Oswald, 1998).

Two theoretical approaches underlie the above conclusions. The first, based on rationality axioms and money-oriented preferences, states that individuals who earn more within a short working period (employees) are more satisfied than their colleagues who earn less, but spend more time at work (self-employed workers). The second approach, propounded by Benz and Frey $(2004,2008)$, known as procedural utility, holds that people who spend more time at work and earn less may claim to be more satisfied with their job. This conclusion is justified by the fact that job satisfaction is not only influenced by results, but also by conditions and procedures leading to these results. For selfemployed workers, factors favoring procedural utility over the utility of income include autonomy, self-determination and the flexibility of working hours (Benz and Frey, 2004; Parasuraman and Simmers, 2001). However, this result is questionable, given the heterogeneous nature of the group of self-employed workers, which motivated studies like Santarelli and Vivareli, (2007) and Block and Koellinger, (2008), to distinguish self-employed by opportunity from self-employed by necessity. Studies which made this distinction used a length of unemployment as differentiating factor between groups of entrepreneurs. However, the particular context of Cameroon's job market requires the use of a different approach.

In fact, the job market in Cameroon is predominantly informal and stands at a $90.5 \%$ rate (INS, 2011). There is a significant number of self-employed workers, which increased after the implementation of SAPs . Moreover, in this market, people who stayed an average of three years without a job opt for self-employment to keep themselves busy while expecting to secure a decent job. This observation accounts for the skepticism caused by the use of the length of 
unemployment as differentiating indicator within self-employed workers' groups. In fact, considering uneducated selfemployed workers' likeliness to be less productive as supported by the human capital (Becker, 1964) or signal theory (Spence, 1973), we see that these workers may spend more time unemployed. In Cameroon however, these uneducated self-employed workers have shorter unemployment periods than educated ones. The reason for this is that, in a context where very few measures are taken to support job seekers, and in the absence of excellent signals, uneducated individuals rapidly opt for self-employment. This explanation accounts for the choice of illiteracy as the differentiating factor between self-employed by necessity and self-employed by opportunity.

Given that several observations suggest that self-employment does not generate enough revenue, the present survey seeks to find out the effect of self-employment on job satisfaction. More precisely, it seeks to determine whether selfemployed workers are more satisfied with their jobs than employees and to evaluate if self-employed workers by necessity are more satisfied than those driven by opportunity. The importance of these questions relies on the fact that they provide empirical evidence (less investigated in developing countries), which may help in reinforcing policies in support of self-employment, and in understanding the reasons behind the choice of employment in a country like Cameroon.

Several methods of causal inference help to estimate the effect of a variable on another, but many of them face the problem of non-random distribution, due to the nature of observational studies (Caliendo and Kopeinig, 2005). This study uses approaches which reproduce the randomisation of observed variables and minimise the bias in the estimated treatment effect (Rosenbaum and Rubin, 1985; Schafer and Kang, 2008; Dehejia and Wahba, 1998). This is why, in addition to the logit model, we used matching techniques which, up till now, were seldom used to analyse the effect of self-employment on job satisfaction (Binder and Coad, 2012). The use of these matching methods helps us ensure good results based on data from the second Cameroonian Household Survey (ECAM 2) carried out by the National Institute of Statistics in 2001.

This study is structured as follows: section 2 deals with literature review, section 3 is a data presentation and methodology, section 4 is the discussion of results and section 5 is the conclusion.

\section{Literature Review}

The traditional microeconomic approach, supported by the positivist movement, significantly contributed to the understanding of social behaviour. Indeed, from this point of view, concrete results like income, consumption of goods and services or payment in cash determine the choice and satisfaction of individuals. Nevertheless, this approach is limited when it comes to determining satisfaction related to job status. Thus, elements which may justify the satisfaction of self-employed workers are different from those defended by the classical economic theory and are found in other social sciences.

In psychology, the theory of the basic psychological needs states that satisfying needs like autonomy, interpersonal relationships and competence is a source of well-being. Added to this theory is , among others, that of Ryan (1995), according to which self-determination influences choice, thus influencing satisfaction. In law, Thibaut and Walker (1975) pioneer work on procedural justice highlight that parties involved in a conflict give equal importance to the methods used in solving their conflict and to the outcome of the said conflict. From a political point of view, it is acknowledged that in a direct democracy (referendum); citizens' satisfaction is justified by the feeling that they are contributing to political life (Bohn and Frey, 1994). These arguments show the vital role played by institutions in individuals' satisfaction, and support the subjectivist approach.

The objectivist approach is opposed to the subjectivist one, as the later is not a scientific method (Frey and Stutzer 2001). Notwithstanding, the consideration of emotions and self-esteem (Loewenstein, 1999) as well as the contributions of Sen $(1995,1997)$, fuelled a larger adoption of the subjectivist approach.

Analysing job satisfaction, therefore, depends on subjective and objective approaches. Thus, as accepted in resultsbased utility, people who spend less time at work and earn more may show a higher level of satisfaction than those who spend more time and earn less. However, according to procedural utility supporters, working conditions are essential (Benz and Frey, 2004 and 2006): people who spend more time at work may show a higher level of satisfaction, despite 
their low incomes. This observation is discussed in several empirical studies.

Hamilton (2000) holds that self-employed workers' high level of job satisfaction is due to non-pecuniary aspects like being his boss, and the flexibility of working hours. Hundley (2001) also holds that flexibility and a high level of autonomy mainly account for self-employed workers' job satisfaction, adding that, using their competence and their high job security are also essential aspects which determine their satisfaction. However, job security, as presented by Hundley (2001), cannot be generalised, as many studies demonstrate that self-employed workers have: a risky portfolio (Moskowitz and Vissing Jorgensen 2002), a more volatile income (Carrington, McCue, and Pierce, 1996 and Kawaguchi, 2003) and a higher probability of bankruptcy (Dunne et al. 1988).

According to Blanchflower and Oswald (1998), self-employed workers' high satisfaction is because this category is made up of optimistic individuals. This argument was developed by Brockhaus and Horwitz (1986), who provided a detailed analysis of self-employed workers' optimism from a psychological point of view.

Another explanation for the high satisfaction of self-employed workers is based on the difficulties in joining this socioprofessional category (Blanchflower and Oswald, 1998; Blanchflower et al., 2001; Kawagushi, 2008). According to Blanchflower and Oswald (1998), if there are barriers to becoming self-employed, then, those who succeed will be more satisfied. This assertion does not apply to the context of developing economies where the rate of self-employment is usually high, considering the negative relationship between an economy's level of development and its selfemployment rate (Kuznetz, 1966; Schultz, 1990; Bregger, 1996). The characteristics of Cameroon's job market seem to show that the status of an informal entrepreneur is due to the saturation of the formal sector (Lewis, 1954; Pradhan, 1994) and constitutes a form of temporary occupation while looking for a better job.

This consideration of entrepreneurship as a constraint is important, especially when we look at the results found by Block and Koellinger (2008), according to which there is a lack of satisfaction for a new category of entrepreneurs, called entrepreneurs by necessity. In their opinion, this category includes people who started an activity after a long period of unemployment and those who lack better job opportunities. This distribution of self-employed workers is very important, given the heterogeneous nature of this group. Block and Koellinger (2008), as well as Binder and Coad (2012), define self-employed by necessity as those who have been unemployed for a long time. Nevertheless, in this study, self-employed by necessity refers to uneducated self-employed workers. This definition is justified by the fact that, according to the signal and/or filter theories (Arrow 1973, Spence 1973), when employers lack information, they use the level of instruction as an inborn productivity signal in workers. This situation forces uneducated people to opt for self-employment, where they encounter no barriers.

As for entrepreneurs by opportunity, Block and Koellinger (2008), just like Benz and Frey (2004 and 2006), point out the pertinence of procedural utility to the understanding of economic behaviour, by showing the importance of both their financial and nonfinancial motivations.

It is worth mentioning that even though the above results concern job satisfaction only, it is not sure if they can be applied to the larger context of life satisfaction. Two assumptions underlie this idea: first and foremost, job satisfaction can largely reflect the joy of having an occupation. This idea had not been explored in previous studies on satisfaction. Secondly, an individual's great satisfaction with his job can make them neglect other important aspects of life such as health, family relationship and friendship (Blinder and Coad, 2012).

From all the studies discussed in this section, it appears that qualitative models, tests of a difference of means or correlation analyses have mostly been used to evaluate the relationship between job status and satisfaction. However, it has been noticed that these methods present some limits, as compared to matching techniques. Also, analyses of the results of these studies show that it is difficult to apply them to every individual in the group. Furthermore, the empirical evidence here is adapted to developed economies only. Thus, there is not enough reason to apply these results to developing economies like Cameroon. Indeed, these economies are characterised by specific job market structure and living conditions, including a significant number of poor employees, an informal sector which comprises most employment, a predominant agricultural sector, and the absence of a support-system for job seekers. 


\section{Data Presentation and Methodology}

Data used in this study is from the second Cameroonian Household Survey (ECAM 2) carried out by the National Institute of Statistics in 2001. ECAM 2 is appropriate here as it provides information on individuals' socio-professional status and their job satisfaction. In addition, it provides important information in various sections concerning health, level of education, economic activity and income of the individuals.

The enquiry is carried out on 56,443 individuals of 0 years and more. This study concerns people of working age only, between 15 and 65 years. Based on this criterion, 25,539 people were excluded from the sample. As the study focuses on the relationship between self-employment and job satisfaction, 12,592 people are excluded from the sample because they don't provide information on job status. Also, 171 people are excluded for failing to give information on job satisfaction. As opposed to Blanchflower (2000) who holds that it would be improper to exclude family allowances because self-employed workers indirectly share their revenue through consumption of household goods, these allowances are excluded in this study for two reasons. Firstly, self-employed workers' autonomy is under hierarchical constraint, which renders them similar to employees. Also, determining their revenue within the family context excludes them from such a group. This restriction, which also applies to unpaid interns, leads us to a sample of 15,160 individuals with 10,091 self-employed, including self-employed workers with employees and those without employees.

Used as a dependent variable, job satisfaction, is evaluated from the following question: "are you satisfied with your main job?" Respondents are expected to provide yes/no answers. The main explanatory variable consists in giving information on the entrepreneurial status of individuals. First, the value of this variable is 1 if the individual is selfemployed and 0 if he is an employee. Secondly, this value is 1 if the individual is uneducated and 0 if he is educated.

\subsection{Descriptive Statistics}

Table 1: Descriptive statistics depending on the status

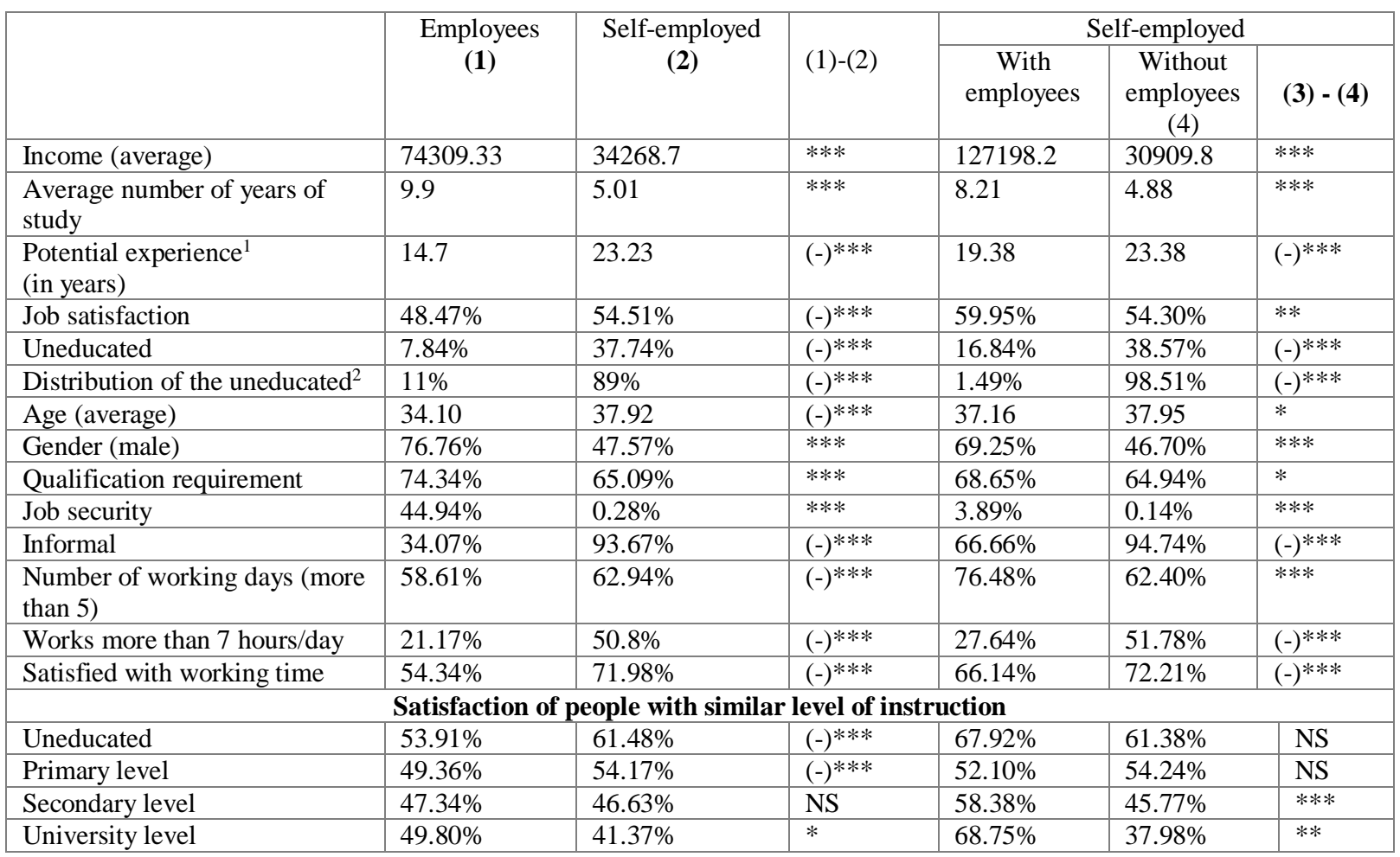

By the authors, from ECAM 2 data

Table 1 notes: Column (1) - (2) represent the significance of the tests of difference of means of columns (1) and (2) as follows: NS $=$ Non significant $* * *=$ significant at $1 \%, * *=$ significant at $5 \%, *=$ significant at $10 \%$.

\footnotetext{
${ }^{1}$ Potential experience is calculated as follows: age minus number of years of study minus 10 (which corresponds to 7 plus 3 , these figures representing the average age at enrollment and the average number of years of unemployment respectively).

${ }^{2}$ This variable shows how all the uneducated are distributed among self-employed and employees, as opposed the "uneducated" variable above, which gives the percentage of uneducated workers in each socio-professional category.
} 
Table 1 summarizes the descriptive statistics of some variables of interest in this study. The first four columns dwell on comparing employees with self-employed workers. The last four columns on their part distinguish the characteristics of self-employed workers depending on whether they have employees or not.

According to a widespread idea in Blanchflower and Oswald, (1998); Blanchflower, (2000); Benz and Frey, (2004); Clark and Senik, (2006); Kawaguchi, (2002); Hundley, (2001); and Benz and Frey, (2004), self-employed workers are relatively more satisfied than employees $(54.51 \%$ against $48.47 \%)$. And this, notwithstanding the fact that their income is a bit less than half the salary of employees, that is, FCFA 34,268.7 against FCFA 74,309.33 for employees, and they almost never have job security. In addition, $93.67 \%$ of these self-employed workers belong to the informal sector, against only $34.07 \%$ of employees.

In this study, uneducated self-employed workers are considered self-employed by constraint, as their lack of education limits their opportunities. This explains the high rate of uneducated self-employed workers, compared to employees, that is, $89 \%$ and $11 \%$ respectively. Educated self-employed workers are considered self-employed by opportunity. This division is guided by Chen (2007) and Fields (2005)'s multi-segmented conception of the job market, which stipulates that the informal sector has an upper segment made up of individuals who chose to be part of it, while the lower segment is made up of those who are there by constraint. Binder and Coad (2012) distinguish self-employed by opportunity from those by necessity, based on the length of unemployment. They consider that people who stayed unemployed for a long time are self-employed by necessity.

Here, we realise that the literacy rate of self-employed workers is more than four times above that of employees. This observation is very pertinent, as $74.34 \%$ of employees against $65.09 \%$ of self-employed workers say qualification is required in their jobs. This is in line with an average difference of four years of studies for employees. Self-employed workers with the same level are more satisfied at the lowest level of instruction but are relatively less satisfied than employees at the university level. Once more, this shows that constraints related to qualification and level of instruction are real, and that these can constitute an obstacle for people who want to secure a paid job. These constraints equally explain illiteracy rates among self-employed workers.

This table equally shows that self-employed workers invest more time at work, and are mostly women. Regardless of these elements, statistics indicate that self-employed workers are relatively more satisfied with their working time. This further stresses the importance of autonomy to job satisfaction as Benz and Frey (2006) point out. As regards the distinction between self-employed with and without employees, table 1 shows that, with the same level of autonomy, the forecast of the main economic theories are verified. This is because self-employed with employees are more satisfied than those without employees, and their average income is four times superior to that of the latter. However, even though self-employed with employees' number of years of study is twice superior to that of those without employees, with the same level of instruction, they are more satisfied only as from the secondary level.

In recent literature on satisfaction, Dolan et al. (2008) conclude that empirical evidence on the relationship between self-employment and satisfaction are mitigated. The weakness of these results may be because the group of selfemployed workers is not homogeneous (Santarelli and Vivarelli, 2007). Vivarelli (1991) states that becoming selfemployed cannot simply be seen in terms of attractiveness (the expected benefits for instance), but also regarding impulse, like unemployment. This is the origin of the debate on the link between job satisfaction and job market access constraints. Fuchs-Schundeln (2009) state that, self-employed workers by a constraint can prove less satisfied because they don't appreciate the lifestyle of self-employed workers. However, it is worth noting that they may be more satisfied, as self-employment comes as a godsend opportunity.

Table 2 examines this debate, distinguishing educated from uneducated self-employed workers. It reveals that uneducated self-employed workers are relatively more satisfied than educated ones. Statistics from this table do not show a significant difference in income between the two groups considered. Nevertheless, uneducated self-employed workers show an average level of satisfaction with their job, working hours and working time, superior to that of their educated pairs. 
Juliette laure Mathou Tchinda, Prof. Huasng Rong Bing

Job Satisfaction of Self-Employed Workers: Empirical Evidence from Cameroon Data

Table 2: Descriptive statistics of the uneducated

\begin{tabular}{|c|c|c|c|}
\hline & \multicolumn{3}{|c|}{ Self-employed } \\
\hline & Uneducated & Educated & \\
& $(5)$ & $(6)$ & $(5)-(6)$ \\
\hline Average income & 39654.96 & 31818.69 & NS \\
\hline Potential experience (years) & 32.06 & 17.77 & $* * *$ \\
\hline Average number of years of study & 0.44 & 7.78 & $* * *$ \\
\hline Job satisfaction & $61.10 \%$ & $50.53 \%$ & $* * *$ \\
\hline Age (average) & 42.52 & 35.13 & $* * *$ \\
\hline Gender (male) & $40.47 \%$ & $51.87 \%$ & $(-)^{* * *}$ \\
\hline Qualification requirement & $64.69 \%$ & $65.34 \%$ & NS \\
\hline Job security & $0 \%$ & $0.43 \%$ & $(-) * * *$ \\
\hline Informal & $97.97 \%$ & $91.05 \%$ & $* * *$ \\
\hline Number of working days:> 5 & $76.48 \%$ & $62.40 \%$ & $* * *$ \\
\hline Works more than 7h/day & $56.36 \%$ & $47.42 \%$ & $* * *$ \\
\hline Satisfied with working time & $78.02 \%$ & $68.3 \%$ & $* * *$ \\
\hline
\end{tabular}

\section{By the authors, from ECAM 2 data}

Table 2 notes: Column (5) - (6) represent the significance of the tests of a difference of means of columns (1) and (2). as follows: NS $=$ Non significant $* * *=$ significant at $1 \%, * *=$ significant at $5 \%, *=$ significant at $10 \%$.

From the above analysis, one can first anticipate that self-employed workers show more job satisfaction than employees, and secondly, that uneducated self-employed workers are more satisfied with work than their educated pairs. However, these descriptive statistics do not show how socio-professional status and constraints related to the choice of a job affect satisfaction. The approaches used in this study to estimate these effects are presented below.

\subsection{Methodology}

\subsubsection{The logit model}

In this study, workers' job satisfaction is described by a concave twice differentiable utility function, whose arguments are individual characteristics of both workers and employment itself. The expressed satisfaction of an individual (i) comes from the utility difference between two job statuses ( $j=$ self-employed or employee), written as follows:

$=(1)$

With a vector of observable characteristics including the logarithm of individual interest, a number of working hours, health condition, level of education, potential experience and control variables affecting job satisfaction such as age, marital status, job security, place of residence, qualification requirements and some hours of work. It is the vector of the parameters associated with these variables.

SE is the binary variable whose value is one if the worker is self-employed and 0 if he is not. Measures the effect of self-employment on satisfaction. It is the term errors vector, independently and identically distributed following a logistic distribution. $\mathrm{a}=$ self-employed and $\mathrm{s}=$ employee.

It is an unobserved latent variable. In reality, only an individual's expressed satisfaction () is observed. Consequently, an individual's satisfaction is presented as follows:

$=(2)$

The probability for an individual with the required profile to be satisfied is expressed by the following equation:

$=\mathrm{E}(3)$ 
We generate the inverse Mills ratio introduced as an explanatory variable in the individual gain functions used in the above equation. This helps in correcting the eventual selection bias as, based on the criteria selected to define the endogenous variable of this study, the sample may prove non-random.

Bearing in mind that SE is a dummy variable, the marginal effect (ME) of self-employment on the probability of being satisfied is the average effect of the marginal change of predicted probability, all the $\mathrm{X}$ variables being constant:

$\mathrm{ME}=(4)$

is a logistic distribution function, is the predicted marginal probability of being satisfied? For all the observations, it is calculated using estimated coefficients. $\mathrm{n}$ is the number of individuals in the sample.

Even though marginal effect represents the average effect of job status on the satisfaction of self-employed workers, the results from the application on the above logit present several limitations related to the model's hypotheses. Firstly, the impact of self-employment on satisfaction is considered constant for all individuals, which does not reflect the reality. Secondly, individuals are introduced into the estimation sample irrespective of the differences between selfemployed workers and employees. This does not guarantee that the difference in satisfaction observed in the results of the logit is the only consequence of the socio-professional status of the individuals. These limitations justify the use of alternative methods based on the calculation of propensity scores. These methods help to ensure good results and to avoid the above-mentioned limitations.

\subsubsection{Propensity Scores Matching}

Before showing the effect of self-employment on satisfaction, it is important to ensure that groups of individuals, that have been formed, are comparable (Rosembaun and Rubin, 1983). PSM used in this study shows that this condition has been respected through matching and the establishment of a "common support" area. The Presentation of this method starts with the prior definition of the treatment and possible results.

In this study, these possible results refer to the satisfaction or non-satisfaction of individuals. The idea an individual "i " has of his satisfaction is determined by treatment conditions defined as follows: treated () corresponding to the selfemployed status, and not treated () corresponding to the employee status. For any individual, the following situations are possible: () describing the job satisfaction of a self-employed and (), that of an employee. Normally, evaluating the effect of self-employed status on individuals' satisfaction at work requires a comparison between the satisfaction of self-employed workers $(())$ and that of employees $(())$. When all the results are observed, the non-biased estimation of the average treatment effect (ATE) is obtained by:

$\mathrm{ATE}=(5)$

With $\mathrm{n}$ representing the number of individuals, the result when every individual has been treated and when not all of them have been treated.

Since the two results cannot be observed simultaneously, a problem of causal inference arises. Greenland et al. (1999) refer to the unobserved result as "counterfactual". In order to include it in evaluating the treatment effect on the result, scholars recommend that the result of an individual who received treatment be compared to that of another who did not. Consequently, this study aims at comparing the satisfaction of self-employed to that of employees.

Although the method is accepted for random laboratory tests, there is, however, a problem at the level of selection bias in observational studies. At this level, the selection bias is due to the uncertainty about self-employed and employees being comparable. Especially when some factors are influencing treatment like job status, which can also influence results or satisfaction, thus raising doubt over the treatment effect on results. Avoiding selection bias requires a Random treatment grant. Therefore, the ATE of equation (1) cannot be estimated in an observational study. However, when the random treatment grant is ensured, the non-bias estimation of ATE can be determined using the difference between the average result of individuals who were treated and those who were not treated. The following expression is obtained: 
With, being the total number of people treated and that of people who were not treated.

Matching guarantees that untreated people, belonging to a group named control group, are not comparable with people from the treatment group. This justifies the use of PSM which primarily consists in using probability calculation to predict the treatment grant for each individual from variables which are likely to influence both the treatment grant and the result, and then comparing the results of people with similar propensity scores (predicted probabilities). The method is mainly based on the following assumptions:

- The Stable Unit Treatment Value Assumption (STUTVA), according to which treatment granted to an individual, does not affect the results of another individual, meaning that there is no interference between individuals.

- Conditional Independence Assumption (CIA) or "unconfoundedness", assumes that the treatment grant mechanism is independent of potential results, considering explanatory variables.

This is a way of solving the problem of self-selection bias in experimental studies. This is to say that selection is exclusively based on observable characteristics and that, all the variables affecting both the treatment grant and the results are observed by the researcher.

- The Common Support Assumption or overlap condition stipulates that the probability of being treated should range between 0 and 1 . This condition suppresses the phenomenon of perfect predictability of treatment grant, considering X. It guarantees that people with similar characteristics have a positive probability of being in the same group as individuals who have received treatment or not.

In this study, propensity scores are obtained from the estimation of a logit model which predicts the probability of being self-employed for all the individuals making up the sample. The logit used here and the one presented earlier have the same explanatory variables. The only difference is at the level of the endogenous variable. Once propensity scores are obtained, several matching techniques may be used to guarantee that the individuals compared are actually comparable, and that any difference observed in the results is an outcome of the treatment.

Several matching techniques are used in this study: The nearest neighbour method with calibre and radius, then without calibre and radius, and finally the stratification method. Concerning the nearest neighbour matching method recommended in this study, it consists of making up a treatment group composed of people who have been treated, and a control group made up of people who have not been treated. Any individual from the control group is paired with individuals considered as their nearest neighbour(s) based on propensity scores. The selection criterion of the nearest neighbours lies in the definition of a calibre or radius. So, when the value of the difference between the propensity score of an individual from the treatment group and that of an individual from the control group is inferior to the value of the defined calibre or radius, the individual is considered the nearest neighbour of the individual from the control group. Once these groups are set up, they are said to be comparable if the average value of their propensity scores is not different after a difference of means test, and if the distribution of explanatory variables is balanced between both groups.

In the stratification method, the sample of the study is divided into propensity scores strata. A stratum, made up of both self-employed workers and employees, is divided into a treatment group and a control group. The two groups are similar and comparable if the propensity scores average value remains unchanged after a difference of means test, and if the distribution of each explanatory variable is balanced in the entire stratum

The ATE is then calculated after the propensity scores matching. However, even though only the nearest neighbour and the stratification methods are presented in this study, it is worth mentioning that other matching techniques may be used (Kernel's method and Mahalanobis, , metric matching, etc.). After obtaining the average effect of self-employment on satisfaction, it is important to test the statistical significance and calculating its standard error. The problem stems from the fact that the treatment effect estimated variance equally includes the variance due to the estimation of propensity scores, common support affectation and probably the order through which the treated individuals (selfemployed) were matched. Lechner (2002) suggested that this problem can be solved using the bootstrap procedure whose replication order on treatment effect's standard deviation is 100 in this study. 


\section{Results}

Considering the context of Cameroon's job market characterised by a long period of unemployment and a predominance of the informal sector which is mostly made up of self-employed workers, this study seeks to find out if, in spite of the disadvantages regarding income and job security, self-employment has a positive effect on satisfaction. This question is important in this study for two reasons. Firstly, it opposes proponents of procedural utility to those of the classical approach to satisfaction based on the indirect utility function. Secondly, it defines the role of constraint on satisfaction through results obtained from workers lacking better job opportunities because of their low level of education.

Table 3 reveals that self-employment positively influences job satisfaction. The results obtained from the logit used are found in

Appendix A. The first estimation of table 3 indicates that the positive influence of self-employment on job satisfaction is ranged at 0.47 . Also, being self-employed increases the probability of being satisfied by $11 \%$.

These results prove that procedural utility is fundamental, meaning that self-employed workers are satisfied because of non-pecuniary determinants such as autonomy, and self-actualisation, etc. Also, the results of the second estimation indicate that at conventionally selected thresholds, there is no significant difference in satisfaction between uneducated self-employed workers and educated ones. These results are different from those found in the literature (Block and Koellinger, 2008, Binder and Coad, 2012).

Nonetheless, it is worth analysing this estimation cautiously, as the logit has limitations. Indeed, as Imbens (2004) points out, this method does not consider variables distribution between the treatment and the control groups. A significant difference in this distribution of groups renders the results less credible, given that these two groups are not comparable per se. Also, the logit's results show that the effect of self-employment is constant for all individuals, which in reality is not true.

Table 3: Effect of self-employment on satisfaction: estimation from a logit

\begin{tabular}{|c|c|c|c|c|c|c|}
\hline \multicolumn{7}{|c|}{ Results of the logit; dependent variable: job satisfaction } \\
\hline & \multicolumn{3}{|c|}{ Self-employed workers/employees } & \multicolumn{3}{|c|}{$\begin{array}{l}\text { Uneducated self-employed workers } \\
\text { Educated self-employed workers }\end{array}$} \\
\hline Variables & Coefficients & $\mathrm{Z}$ & $\mathrm{ME}$ & Coefficients & $\mathrm{Z}$ & ME \\
\hline Job status & $\begin{array}{c}0.474 * * * \\
(0.085)\end{array}$ & 5.54 & $\begin{array}{c}0.117 * * * \\
(0.021)\end{array}$ & $\begin{array}{c}0.238 \\
(0.179)\end{array}$ & 1.33 & $\begin{array}{c}0.058 \\
(0.043)\end{array}$ \\
\hline Mills Ratio & $\begin{array}{c}0.440 * * * \\
(0.120)\end{array}$ & 3.66 & & -0.050 & & \\
\hline Number of observations & 4.823 & & & 3.046 & & \\
\hline Adjusted $\mathrm{R}^{2}$ & 0.042 & & & 0.027 & & \\
\hline
\end{tabular}

Notes to table 3: ***=significance at $1 \%$; ME=marginal effect Standard deviations are in brackets. The job status (value in the second column is 1 if the individual is self-employed and 0 if he is an employee. In the fifth column, the value is 1 for uneducated self-employed workers and 0 for educated, employed workers. Each regression contains the following variables whose results are found in Appendix A: job status, income, inversed Mills Ratio, number of working hours, health condition, level of instruction, potential experience; age, marital status, a sector of activity, place of residence, qualification requirements and working time. The fifth column does not contain enough observations, as it considers only self-employed workers.

These limits motivate us to examine the results of the alternative approach, which is PSM. This method helps us deal with the limitations of the logit, and is advantageous as it does not require assumptions on the functional form (Hussingerr, 2008). 
The first step of the PSM consists in calculating propensity scores and, based on these scores, matching similar individuals. Here, matching guarantees that compared self-employed workers and employees do not present differences which may affect the results. Figure 1 presents propensity scores distribution of self-employed workers and employees before matching.

It shows how much the distribution of the predicted probability of being self-employed differs among employees and self-employed workers. Thus, comparing results of treatment between fundamentally different groups does not guarantee that the difference in the results of these groups is a result of treatment. To guarantee that employees and self-employed workers are comparable and that any difference in satisfaction is due to self-employment, we will use nearest neighbour matching to compare similar individuals only.
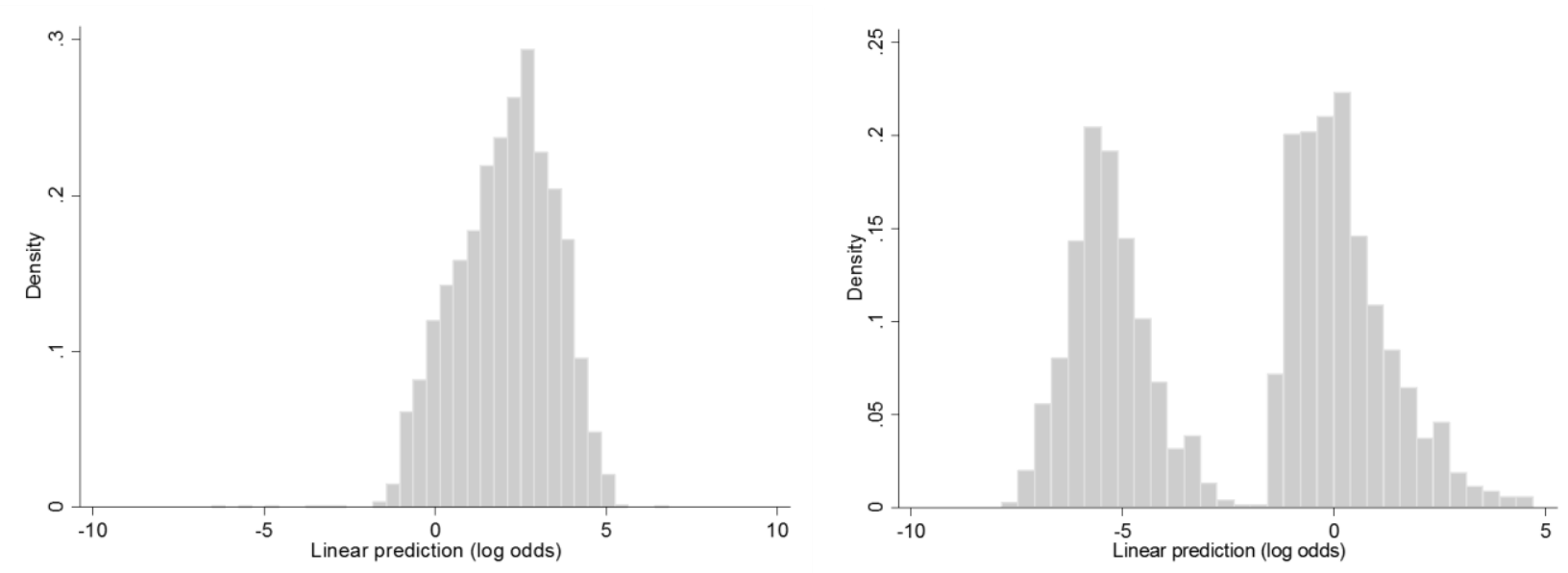

Figure 1: Propensity scores distribution before matching: on the left, the distribution of self-employed workers, and that of employees on the right.

Two individuals are said to be similar if they present similar characteristics. All the characteristics of an individual are found in their matching score. Matching scores made up of the predicted probability for an individual to be selfemployed are obtained in logit regression. Job satisfaction will, therefore, be compared only between individuals whose propensity scores are close. As recommended in the literature (Caliendo and Kopeinig , 2005), the value of the calibre used in this study to match self-employed workers and employees is 0.25 where refers to the propensity scores standard deviation, obtained in the entire original sample.

Figure 2 presents the propensity scores distribution obtained after nearest neighbour matching. In order to guarantee that people with similar characteristics have a positive probability of being in the same group, the common support condition is set and helps to dismiss individuals who do not respect this PSM assumption. The individuals isolated because of this assumption are represented by the green segment of figure 2.

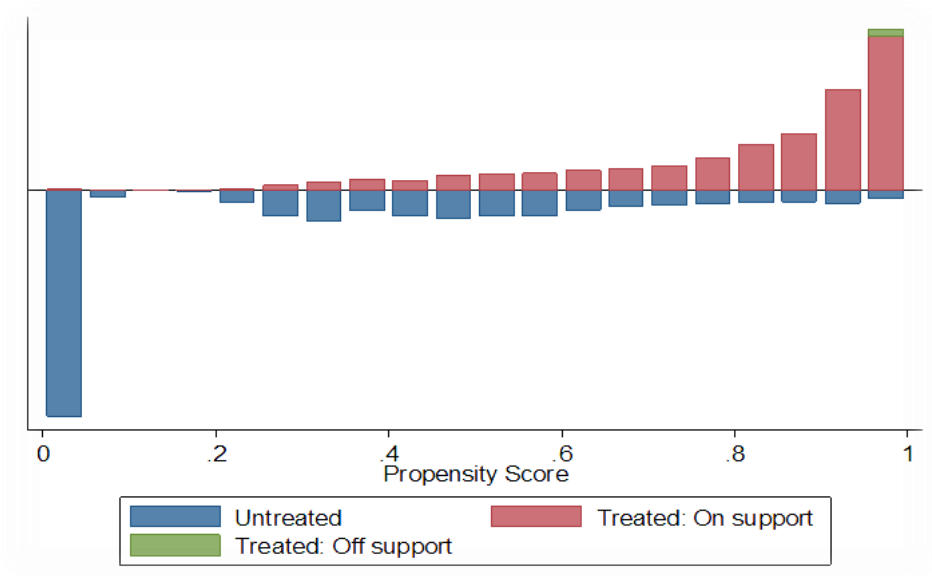

Figure 2: Propensity scores distribution after nearest neighbour matching 
Since matching guarantees that the constituted groups of individuals are comparable, the ATE can be calculated. In accordance with the PSM requirements, preliminary analyses indicate the explanatory variables' distribution is balanced, this regardless of the socio-professional status (results are not presented). Table 4 presents the average treatment effect obtained after using several matching techniques. In order to ensure good results, the outcomes of the four methods have been confronted with and without common support. These methods are the nearest neighbour method without calibre, the nearest neighbour method with a calibre with a 0.25 value, the stratification method and the radius method. We notice that the robustness of the radius method used here is evaluated through the execution of several radius scales.

In any case except for stratification, the average effect of self-employment on job satisfaction is significant and positive. These results validate that obtained in table 3 with logit. We notice that models respecting common support condition are not so different. In a general sense, there are fewer people in models respecting common support condition as expected.

In radius matching models, the number of unemployed workers reduces as the radius decreases. This reduction is considerable when the radius used reaches a 0.0001 value.

Table 4: Estimation of the effect of self-employment on satisfaction Propensity Scores Matching

\begin{tabular}{|c|c|c|c|c|c|c|c|c|}
\hline & \multicolumn{3}{|c|}{ Without common support } & \multicolumn{3}{c|}{ With common support } \\
\cline { 2 - 8 } & $\begin{array}{c}\text { Number of } \\
\text { self- } \\
\text { employed } \\
\text { workers }\end{array}$ & $\begin{array}{l}\text { Number of } \\
\text { employees }\end{array}$ & ATT & $\mathrm{t}$ & $\begin{array}{c}\text { Number of } \\
\text { self- } \\
\text { employed } \\
\text { workers }\end{array}$ & $\begin{array}{c}\text { Number } \\
\text { of } \\
\text { employee } \\
\text { s }\end{array}$ & ATT & $\mathrm{t}$ \\
\hline $\begin{array}{c}\text { Nearest neighbour } \\
\text { matching }\end{array}$ & 10.091 & 3.901 & 0.11 & 3.41 & 3.004 & 611 & 0.12 & 3.09 \\
\hline $\begin{array}{c}\text { Calipter matching (0,25.= } \\
\text { 0,73) }\end{array}$ & 3.044 & 1.779 & 0.13 & 7.84 & 3.002 & 1.779 & 0.13 & 7.8 \\
\hline Radius matching (0.1) & 3.044 & 1.779 & 0.14 & 4.71 & 3.002 & 1.779 & 0.14 & 4.75 \\
\hline Radius matching (0.01) & 3.044 & 1.779 & 0.13 & 3.79 & 3.002 & 1.779 & 0.13 & 3.82 \\
\hline Radius matching (0.001) & 2.443 & 1.779 & 0.11 & 3.18 & 2.429 & 1.779 & 0.11 & 3.31 \\
\hline Radius matching (0.0001) & 566 & 1.779 & 0.13 & 3.09 & 564 & 1779 & 0.13 & 3.16 \\
\hline Stratification matching & 10.091 & 5.069 & 0.006 & 0.697 & 3.044 & 1.708 & 0.006 & 0.697 \\
\hline
\end{tabular}

Notes to table 4: All propensity scores matchings are represented by the probability for each individual to be self-

employed. These scores are obtained from logit estimations with the following explanatory variables: revenue logarithms, number of working hours, health condition, level of instruction, potential experience, age, marital status, a sector of activity, place of residence, qualification requirements and proportion of working time.

The standard error used to calculate the t statistics is the ATT's standard deviation obtained after 100 bootstrap replications.

In a general sense, the results obtained with matching techniques once more demonstrate that procedural utility is the best approach, (Benz and Frey, 2008), as compared to the predictions of the classical approach. In fact, even though self-employment is associated with low income and no job security as seen in the previous section, it has a positive effect on job satisfaction. These results are similar to those of Binder et Coad (2012), Blanchflower (2000), Benz et Frey (2004, 2008), Clark et Senik (2006), and may be justified by the fact that self-employed workers, unlike their employed counterparts who are under hierarchy, are autonomous, self-actualised and self-determined in their decisionmaking process. The results obtained in the table above show that although the pecuniary aspect is important in determining job satisfaction, the non-pecuniary aspect also plays a significant role and can compensate for the low income generated by employment. Hamilton (2000) recognises this fact and reveals that entrepreneurial behaviour can be contrary to axioms of rational decision-making in a traditional microeconomy.

However, the utility that individuals obtain the results of their decisions are not only influenced by circumstances leading to those decisions but also depends on conditions under which results, which highly influenced procedural utility, are obtained. In this light, the constraint related to the choice of an employment can highly influence employees' 
satisfaction. This leads to the distinction between self-employed by choice and self-employed by necessity.

Following this distinction, empirical studies (Binder and Coad, 2012; Block and Koellinger, 2008) are unanimous on the fact that self-employed by necessity are less satisfied than self-employed by choice. Next in this work is, therefore, to verify the result obtained considering illiterates as self-employed by necessity.

In order to ensure that uneducated self-employed workers and educated ones are comparable, propensity scores are calculated from a logit whose dependent variable bears the value 1 , for uneducated self-employed individuals and 0 for educated ones. Explanatory variables are stated bellow: Area of residence, age, gender, marital status, total time spent at work, health condition, qualification requirement, job security, level of education and logarithm of income. The results obtained from the logit are presented in table A.4 in an appendix. The propensity scores distribution obtained is presented in figure 3 below.
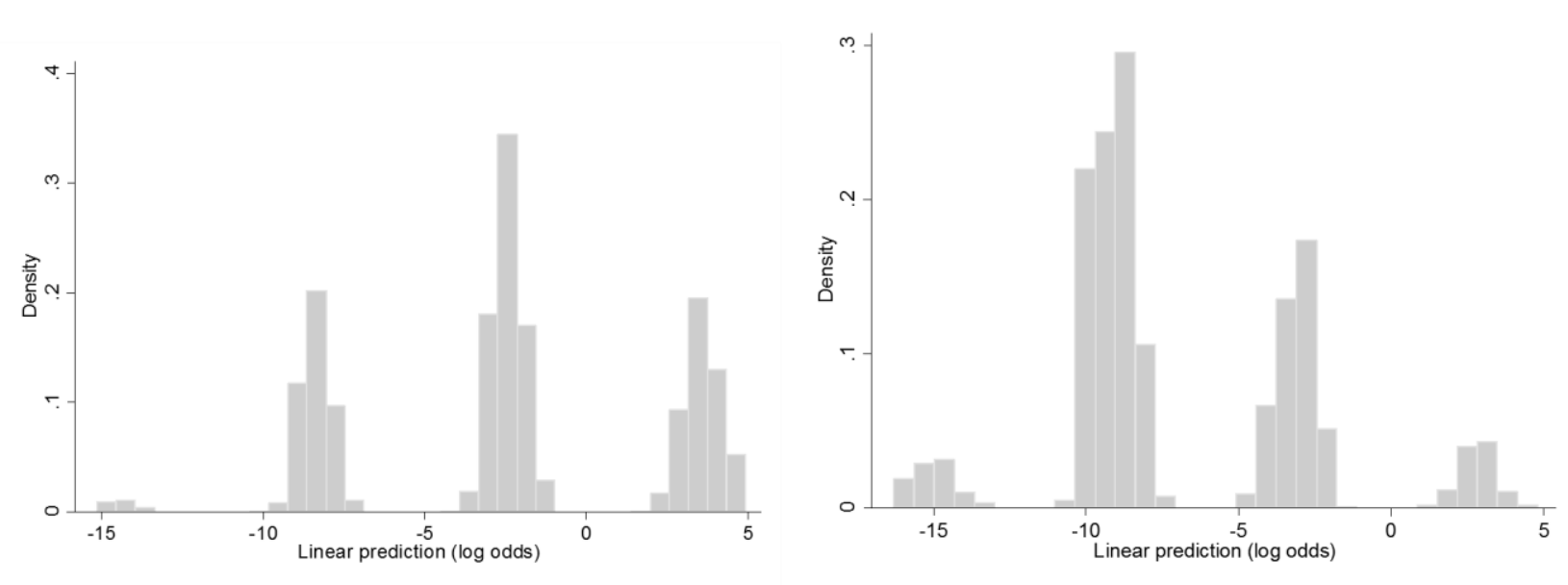

Figure 3: propensity scores distribution before matching: on the left; the distribution of self-employed workers, and that of employees on the right.

Radius matching helps to obtain a sample of comparable individuals whose distributions are similar as presented in figure 4 above. Heckman, LaLonde and Smith (1999) emphasize that respecting the common support condition guarantees that people with the same characteristics have a high probability to be uneducated or not. Matching equally helps to reduce the bias in the explanatory variables used in the calculation of propensity scores. Table 6A in appendix outlines the bias associated with each explanatory variable before and after matching.

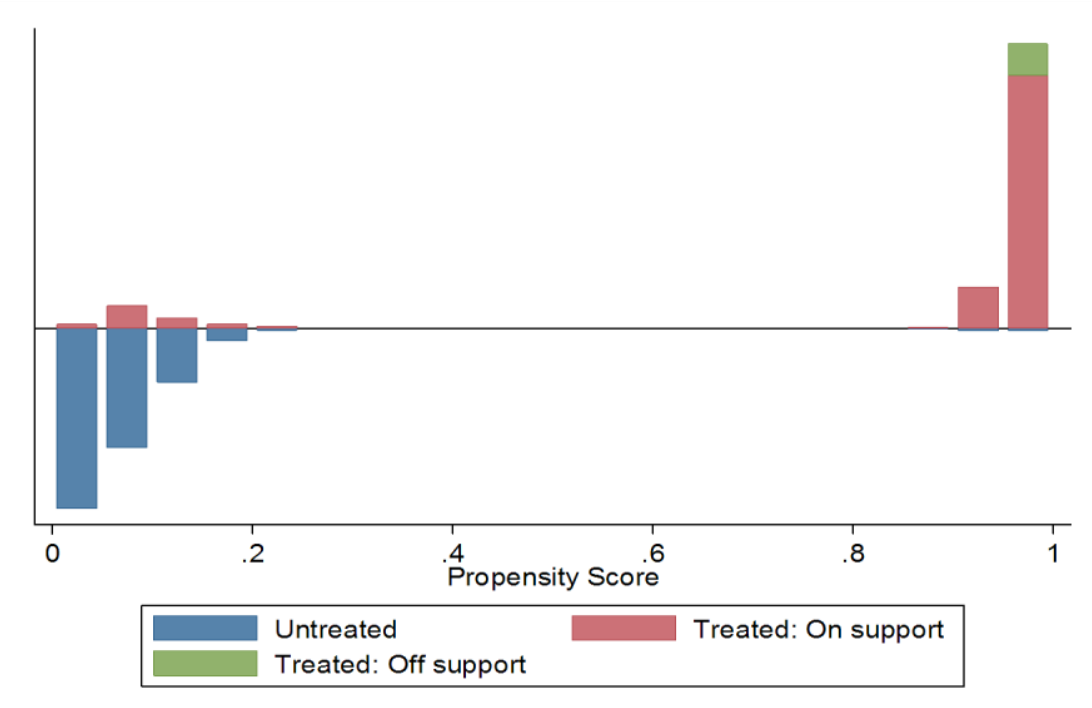

Figure 4: Propensity scores matching after radius matching. 
After matching, the calculation of the average effect of illiteracy on the satisfaction of uneducated individuals is presented in table 5 .

The table summarises the results obtained after using three matching techniques, with or without common support. Still, the robustness of the radius method is tested after using four different values of the radius. Non-compliance with the common support condition leads to a greater sample although the illiteracy effect is not that different, whether the condition is respected or not. In accordance with Binder and Coad (2014), self-employed by necessity are less satisfied irrespective of the non-significance at conventionally selected thresholds.

Table 5: Estimation of the effect of self-employment by constraint on satisfaction: Propensity Scores Matching

\begin{tabular}{|c|c|c|c|c|c|c|c|c|}
\hline & \multicolumn{4}{|c|}{ Without common support } & \multicolumn{4}{|c|}{ With common support } \\
\hline & $\begin{array}{c}\text { Number of } \\
\text { uneducated self- } \\
\text { employed } \\
\text { workers }\end{array}$ & $\begin{array}{l}\text { Number of } \\
\text { educated } \\
\text { self- } \\
\text { employed } \\
\text { workers }\end{array}$ & OWT & $\mathrm{T}$ & $\begin{array}{c}\text { Number of } \\
\text { uneducated self- } \\
\text { employed } \\
\text { workers }\end{array}$ & $\begin{array}{c}\text { Number of } \\
\text { educated self- } \\
\text { employed } \\
\text { workers }\end{array}$ & OWT & $\mathrm{t}$ \\
\hline $\begin{array}{c}\text { Nearest neighbour } \\
\text { matching }\end{array}$ & 3.807 & 4.312 & -0.019 & -0.16 & 982 & 138 & -0.035 & -0.29 \\
\hline $\begin{array}{c}\text { Calipter matching } \\
(0,25 .=0,09)\end{array}$ & 982 & 2.107 & -0.016 & -0.20 & 898 & 2.107 & -0.043 & -0.27 \\
\hline Radius matching (0.1) & 982 & 2.107 & -0.006 & -0.08 & 898 & 2.107 & -0.014 & -0.17 \\
\hline Radius matching (0.01) & 982 & 2.107 & -0.028 & -0.22 & 898 & 2.107 & -0.053 & -0.46 \\
\hline Radius matching (0.001) & 505 & 2.107 & -0.045 & -0.42 & 488 & 2.107 & -0.034 & -0.32 \\
\hline $\begin{array}{l}\text { Radius matching } \\
\qquad(0.0001)\end{array}$ & 133 & 2.107 & -0.021 & -0.30 & 132 & 2.107 & -0.014 & -0.20 \\
\hline Stratification matching & - & - & - & - & 982 & 1.264 & -0.023 & -0.20 \\
\hline
\end{tabular}

Notes to table 4: Every propensity scores matching is represented by the probability for each individual to be selfemployed. These scores are obtained from a logit whose explanatory variables are the following: place of residence, age, gender, marital status, number of working hours, level of instruction, and the income logarithm. The standard error used to calculate the t statistics is ATT's standard deviation obtained after 100 bootstrap replications

This low level of satisfaction of self-employed workers by necessity is explained by the fact that they don't aspire to be self-employed. The non-fulfilment of their desire to secure a paid job is reflected in their low job satisfaction. In addition, utility due to autonomy is a basic psychological need (Ryan and Deci, 2000). As Block and Koellinger (2008) points out that these two explanations show a less explored aspect of literature on procedural utility, which is the lack of viable options.

The lack of options can surely influence job satisfaction negatively, but it is worth mentioning that it can equally be advantageous, as having a job is enough to highly satisfy self-employed workers by necessity. Even though this possible result has not been explored before, it is obvious that, if we sacrifice the concept of job satisfaction to concentrate on a larger concept like life satisfaction, then such a situation may occur. This topic has not been subject to several investigations, as the only people at our knowledge who explored it are Binder and Coad (2014).

\section{Conclusion}

The present study aimed at examining the effect of self-employment on satisfaction. Given the characteristics of selfemployment, potential answers to this question spark off the debate opposing two utility approaches, namely, resultsbased utility and the procedural approach which were used to obtain the results. The application of the logit model as well as many matching techniques based on the calculation of propensity scores leads us to the conclusion that selfemployment positively affects job satisfaction. In accordance with previous studies on this topic, it is revealed that even though self-employed workers earn less money and do not have the same level of job security, they are still more satisfied than employees. This study shows that despite the fact that self-employed workers spend long hours at work, they are more satisfied with their working time, which proves that autonomy is a major factor of satisfaction. Autonomy goes in line with procedural utility, as opposed to results-based utility. In addition, the heterogeneous nature 
of the group of self-employed workers explains why this study distinguishes self-employed workers by necessity, that is, those who work to avoid unemployment, from self-employed workers by opportunity. This distinction leads to the conclusion that self-employed workers by necessity are less satisfied than self-employed workers by opportunity, even though this result is not significant at commonly selected thresholds. The importance of knowing the effect of job satisfaction is that, beyond confronting the different utility approaches, evidence obtained in this study suggests the consolidation of policies supporting self-employment. Furthermore, the low satisfaction of uneducated self-employed workers whose number is considerable draws the attention of policy creators on the fact that a lot still needs to be done in order to keep people in school as long as possible. Most especially as $48.6 \%$ of school non-attendance or school dropout (INS, $2011^{\circ}$ ) are justified by the lack of financial means. Also, leaving school for training or a job occupies the second position regarding rate among people aged six or more. The results obtained in this study may be completely different when it comes to life satisfaction, which comprises other aspects than those related to employment. Much work is still to be done in this area. Among other aspects, the heterogeneity of the group of self-employed workers can guide studies on the comparison between the satisfaction of self-employed workers with employees and that of selfemployed workers without employees. Such an analysis is guided by the idea that the autonomy of self-employed workers with employees may be seriously hindered by the management of their employees, even though they are more likely to be successful than self-employed workers without employees.

\section{References}

- Arrow, K.J. (1973). "Higher education as a filter." Journal of Public Economics, 2, 193-216. Crossref

- Benz M. and B. Frey (2004): Being independent raises happiness at work, In: Swedish Economic Policy Review, Vol. 11, No. 2, 95-134.

- Benz M. and B. Frey (2008): Being independent is a great thing - Subjective evaluations of self-employment and hierarchy, In: Economica, Vol. 75, No. 298, 362-383. Crossref

- Binder, M \& Coad, A. (2012). Life Satisfaction and Self-employment: A Matching Approch. Small Bus Econ DOI 10.1007/s11187-011-9413-9. Crossref

- Blanchflower, D., \& Oswald, A.(1998). What makes an entrepreneur? Journal of labor Economics, 16(1), 26-60. $\underline{\text { Crossref }}$

- Blanchflower,D.G. (2000). Self-employment in OECD countries, Labour Economics,7,pp. 471-505. Crossref

- Block, J., \& Koellinger, P. (2008). I can't get no satisfaction: Necessity entrepreneurship and procedural utility. Tinbergen Institute Discussion Paper, TI 2008-078/3.

- Bohnet, I. and B. S. Frey (1994). Direct-Democratic Rules: The Role of Discussion. Kyklos 47 (3): $341-354$. Crossref

- Bohnet, I. and Frey B. S. (1999). 'Social Distance and Other-Regarding Behavior in Dictator Games: Comment', American Economic Review, vol 89(1), pp. 335-339. Crossref

- Bregger, J.E. (1996). Measuring self-employment in the United States, Monthly Labor Review, January/February, 3-9.

- Brockhaus, R. H., and P. S. Horwitz (1986), "The Psychology of Entrepreneur," in The Art of Science of Entrepreneurship, ed. by D. L. Sexton, and R. W. Smilor. Ballinger, Massachusetts.

- Caliendo, M., \& Kopeinig, S. (2005). Some practical guidancefor the implementation of propensity score matching. IZA Discussion papers $\mathrm{N}^{\circ} 1588$.

- Carrington W., McCue K. and B. Pierce (1996): The role of employer/employee interactions in labor market cycles - Evidence from the self-employed, In: Journal of Labor Economics, Vol. 14, No. 4, 571-602. Crossref

- Chen, M.A. (2007) Rethinking the Informal Economy - Linkages with the Formal Economy and Formal Regulatory Environment, DESA Working Paper 46, http://www.un.org/esa/desa/papers/2007/wp46_2007.pdf

- Clark A.E. and C. Senik (2006): The (unexpected) structure of "rents" on the French and British labour markets, In: Journal of Socio-Economics, Vol. 35, No. 2, 180-196. Crossref

- Deci, E. L., \& Ryan, R. M. (2000). The 'what' and 'why' of goal pursuits: Human needs and the self-determination of behaviour. Psychological Inquiry, 11, 227-268. Crossref

- Dehejia, R., Wahba, S.,1998. Causal effects in non-experimental studies: re-evaluating the evaluation of training programs, NBER Working Papers 6586, National Bureau of Economic Research, Inc.

- Dolan, P., Peasgood, T.,\&White,M. (2008). Do we really know what makes us happy? A review of the economic literature on the factors associated with subjective well-being. Journal of Economic Psychology, 29(1), 94-122. $\underline{\text { Crossref }}$ 
- Dunne, Timothy, Mark J. Roberts and Larry Samuelson (1988). Patterns of Firm Entry and Exit in US Manufacturing Industries, Rand Journal of Economics. 19: 495-515. Crossref

- Fields, G.S. (2005) A Guide to Multisector Labor Market Models, World Bank Social ProtectionDiscussionPaper05/05, http://siteresources.worldbank.org/SOCIALPROTECTION/Resources/SPDiscussion papers/Labor-Market-DP/0505.pdf

- Frey, B. S. and Stutzer, A. (2001). What Can Economists Learn from Happiness research? Working paper $\mathrm{N}^{\circ} 80$. Journal of Economic Literature, 40, 2002, pp. 402-435.

- Fuchs-Schundeln, N. (2009). On preferences for being self-employed. Journal of Economic Behavior \& Organization,71(2), 162-171. Crossref

- Greenland, S., Pearl, J., Robins, J., 1999. Causal diagrams for epidemiologic research. Epidemiology 10, 37-48. Crossref

- Hamilton, B. (2000). Does entrepreneurship pay ? An empirical analysis of the returns to self-employment. Journal of Political Economy, 108(3), 604-631. Crossref

- Hanglberger, Dominik and Merz, Joachim (2011), "Are Self-Employed Really Happier Than Employees? An Approach Modelling Adaptation and Anticipation Effects to Self-Employment and General Job Changes. IZA Discussion Paper, N. 5629. Crossref

- Heckman, J., R. LaLonde, and J. Smith (1999): IThe Economics and Econometrics of Active Labor Market Programs," in Handbook of Labor Economics Vol.III, ed. by O. Ashenfelter, and D. Card, pp. 1865\{2097. Elsevier, Amsterdam.

- Hundley, G. (2001).Why and when are the self-employed more satisfied with their work?. Industrial Relations: A Journal of Economy and Society, 40(2), 293-316. Crossref

- Hussinger, K. (2008). R\&D and subsidies at the firm level: An application of parametric and semiparametric twostep selection models. Journal of Applied Econometrics, 23(6), 729-747. Crossref

- Hyytinen A. and O.-P. Ruuskanen (2007): Time use of the self-employed, In: Kyklos, Vol. 60, No. 1, $105-122$. Crossref

- Imbens, G. (2004): "Nonparametric Estimation of Average Treatment Effects under Exogeneity: A Review," The Review of Economics and Statistics, 86(1), 4-29. Crossref

- Kawaguchi, D. (2003), "Human Capital Accumulation of Salaried and Self-Employed Workers," Labour Economics, 10(1), pp.55-71. $\underline{\text { Crossref }}$

- Kawaguchi, D. (2008). Self-employment rents: Evidence from job satisfaction scores. Hitotsubashi Journal of Economics, 49(1), 35-45.

- Krashinski, H. (2004), "Evidence from the Self-Employed on Changing Wages for Less-Educated Men in the 1980 's," forthcoming in Industrial and Labor Relations Review.

- Kuznetz, S. (1966). Modern Economic Growth: Rate, Structure, and Spread, New Haven: Yale University Press.

- Lechner, M. (2002). "Some practical issues in the evaluation of heterogenous labour market programmes by matching methods," Journal of the Royal Statistical Society, A, 165, 59-82. Crossref

- Lewis, W. (1954) 'Economic Development with Unlimited Supply of Labor', Manchester School of Economics and Social Studies, 22: 139-91. Crossref

- Lind, E. Allan and Tom R. Tyler (1988). The Social Psychology of Procedural Justice. New York: Plenum Press. Crossref

- Loewenstein, George (1999). Because It Is There: The Challenge of Mountaineering for Utility Theory. Kyklos 52(3): 315-343. Crossref

- Moskowitz, T. J., and A. Vissing-Jorgensen (2002), "The Returns to Entrepreneurial Investment: A Private Equity Premium Puzzle?," American Economic Review, 92(4), pp.745-778. Crossref

- Noorderhaven, N., Thurik, R., Wennekers, S., \& Van Stel, A. (2004). The role of dissatisfaction and per capita income inexplaining self-employment across 15 European countries. Entrepreneurship Theory and Practice, 28(5), 447-466. Crossref

- Pradhan, M. (1995) Sector Participation Decisions in Labor Supply Models. Washington, D.C.: World Bank, pp. 132. Crossref

- Rapport principal de l'Institut National de la Statistique (2011). "Deuxième Enquête sur l'Emploi et le Secteur Informel au Cameroun (EESI2)". Phase 1: Enquête sur l'emploi. P 91

- Rosenbaum, P., and D. Rubin (1983): The Central Role of the Propensity Score in Observational Studies for Causal Effects," Biometrika, 70, 41-50. Crossref

- Rosenbaum, P.R., Rubin, D.B., 1985. Constructing a control group using multivariate matched sampling methods that incorporate the propensity score. American Statistician 39, 33-38. 
- Ryan, R. M. (1995). Psychological needs and the facilitation of integrative processes. Journal of Personality, 63, 397-427. Crossref

- Ryan, R. M., Deci, E. L., Grolnick, W. S., \& LaGuardia, J. G. (2006). The significance of au-tonomy and autonomy support in psychological development and psychopathology. In D. Cicchetti \& D. Cohen (Eds.) Developmental Psychopathology: Volume 1, Theory and Methods (2nd Edition, pp. 295-849). New York: John Wiley \& Sons.

- Santarelli, E., \& Vivarelli, M. (2007). Entrepreneurship and the process of firms' entry, survival and growth. Industrial and Corporate Change, 16(3), 455-488. Crossref

- Schafer, J.L., Kang, J., 2008. Average causal effects from nonrandomized studies: a practical guide and simulated example. Psychological Methods 13 (4), 279-313. Crossref

- Schultz, T.P. (1990). Women's changing participation in the labor force: a world perspective, Economic Development and Cultural Change 38, 457-488. $\underline{\text { Crossref }}$

- Sen, A. K. (1997). Maximization and the Act of Choice. Econometrica 65 (4): 745-779. Crossref

- Sen, Amartya K. (1995). Rationality and Social Choice. American Economic Review 85(1): 1-24.

- Spence, M. (1973). "Job market signaling." Quarterly Journal of Economics, 87, 355-374. Crossref

- Thibaut, J., \& Walker, L. (1975). Procedural Justice. Hillsdale, NJ: Lawrence Erlbaum.

- Vivarelli, M. (1991). The Birth of New Enterprises. Small Business Economics, 3(3), 215-223.Crossref 